\title{
The CLINICAL ASSESSMENT OF EMOTIONAL FACTORS IN DISEASES OF THE SKIN
}

\author{
By Lewis Couper, M.B., Ch.B., D.P.M., and J. H. Twiston Davies, M.A., M.B., B.Ch. \\ Winwick Hospital, Lancashire
}

The dispensary method of medical practice has been imposed on many of us by the rapid growth of a demand-born of the changing structure in a previously healthy society-which has overtaken the supply of useful knowledge and sound experience. There is, however, little evidence that this universal provision of free medicines has been at all successful in reducing the incidence, severity or duration of non-specific sickness. But it is, of course, equally true to say that the best possible practice of medicine would be of no use for this purpose, in a society that is not determined to be healthy or one in which the rewards of infirmity are dispensed by the same hands as those which aspire to relieve it. The function of doctor has been submerged by economic pressure in that of the dispenser of benefits and nostrums. His conscience has been lulled by dreams of the therapia magna sterilisans often so nearly achieved, and his patients have been led to expect nothing less. Moreover, many general practitioners, to judge from their discussion of papers read and from their more private confidences, prefer that the consultant should help to maintain their tottering prestige by descending to the same level and by demonstrating his own failure to succeed with methods that are similar, than that he should take over the role that they have so reluctantly had to abandon themselves, namely that of confessor, friend and advisor in the art of healthy living. Moreover, the average patient prefers a 'cure' by such simple magic if he can get it; not dreaming that it has no possible chance of being a permanent one.

Of course there remain a few things for which the dermatologist has an active line of treatment, e.g. destruction of warts or excision of a neoplasm or mole. But it is too often the case that such work has been taken out of his hands as soon as he has developed the method, as for example, in the $\mathrm{X}$-ray epilation of ringworm, the radium treatment of cutaneous carcinoma and the specific treatments of syphilis and lupus. Nevertheless he is still allowed to prescribe symptomatic relief for acute inflammations, a placebo or near-placebo for tinea circinata, reassurances for the self-limiting pityriasis rosea or for the long-term happy ending of strawberry naevus and granuloma annulare. But none of these things presents much challenge to his skill and they constitute only a small part of his clinical material. But the main task of the dermatologist of today is the restoration to health of persons suffering from non-specific conditions of the skin which prevent them, or which they believe to be preventing them, from living happy and useful lives. Some of these conditions are, in the present state of our knowledge, incurable and the patient must be taught either to ignore themb or to thole them with the necessary fortitude? others, and these fortunately include most of those intrinsically capable of causing disability, are either curable in the material sense or their power of disabling the patient can be so reduced as not to matter. It is in cases of just this kind that cooperation between dermatologist and psychiatrist can be the most valuable and in this paper we attempt to show how they are to be recognized.

The dermatologist cannot always expect the patient to supply his own diagnosis, for without doubt it is in the patient who acts perfectly normally, betrays no perversity of feeling and in whom we arrive at the diagnosis on the strength of physical signs alone, that the most favourable results are forthcoming from psychiatric handling. Now the dermatologist generally first of all asks to see the lesions of which the patient is complaining. He must there be on the lookout for a certain untidiness, non-conformity or non-descriptitude in them. For example, one labium of the vulva or just the anterior half of the anus may be lichenified. Perhaps any lesion in this part of the body is suspect. Certainly lichenification in the neighbourhood of the perineum in the male is. Sometimes the rash affects an area adventitiously associated with sexual experience, e.g. anterior 
aspect of thighs, sacrum. Perhaps the distribution of symptoms and signs is notional as opposed to anatomical, e.g. bathing drawers, below knees only, etc. Often a patch of obvious contact dermatitis occurs on some part, e.g. the front of the neck where it could not be by accident. In other cases the patient is reticent about the obvious relics of therapeutic accidents. Digital excoriations, the artificial aspect of the eruption itself or the convenience of its position for the purposes of scratching may occasionally point an obvious way but the signs are rarely so unmistakable as those $I$ have just mentioned. More subtle indications are the unusual site for a common eruption, e.g. discoid eczema on the belly, or a persistent solitary lesion of a condition normally multiple, e.g. lupus erythematosus or psoriasis. A boil has lasted for six months or an attack of bullous impetigo has been going on for two years. Again the condition presented may be a perfectly typical example of a common disease but occurring at the wrong age, for instance papular urticaria in an adult, the clinical picture of infantile facial eczema in an adolescent or the recrudescence of juvenile acne after it has once disappeared.

It may be that we are surprised to discover two or three quite distinct diseases going on at the same time. Or it may happen that the patient has one of the many conditions that have been labelled ' neurotic,' for example, angioneurotic oedema, neurodermatitis, ulcus mucosae oris neuroticum, rosacea, alopecia areata, stocking erythema or even he may present no visible lesion at all. Worse still he may indicate and complain of normal features such as the sebaceous glands on the scrotum. The skin itself may betray a ' faiblesse irritable,' hyperhidrosis, 'gooseflesh,' factitious urticaria or merely the patient's account of some part of it no longer standing up to normal usage. We must be on the look out for all sorts of facial gesticulatory or respiratory tics, blushing or multiple abdominal scars. Finally the patient may exhibit intimate portions of his anatomy with excessive complaisance, or there may be a morbid shyness, as is so often the case with the lady who may show unmistakable.signs of having been ready enough to display her charms in another place.

Having looked at the rash we inspect the patient himself. He may be excessively juvenile in appearance or he may use infantile gestures. There may be overt signs of active anxiety, 'la belle indifference' or perhaps just relics of nail biting. Perhaps he or she is accompanied by a mother of uncompromisingly severe countenance who will attempt to take an active part in the examination of the patient and demand to be told how 'we' are to apply the ointment; maybe he is just a male who has been sent by wife or girl friend. But perhaps the real patient is actually the mother of the ostensible patient who may have anything from a severe infantile eczema to some non-existent pimple.

Our patient is now allowed to talk. In answer to $C$ the question 'How long?' it turns out that the $\overrightarrow{\vec{F}}$ trouble started just after father died, or just after $\stackrel{\oplus}{\rightarrow}$ fixing the date for the wedding, or just before starting home on leave, or before leaving South Africa for a holiday, or on the way home after demobilization. Any such points may be of $\stackrel{\varpi}{\square}$ interest. Exceptionally, of course, the patient क may remember that the attacks coincide with an $\overrightarrow{0}$ anniversary or develop only on Monday mornings, or exactly so many days before each period and so $\vec{\omega}$ on. An anxiety to blame some accident or other external influence should always arouse suspicion. More obviously relevant is the story that the condition is regularly altered by environmental change $\underline{\omega}$ or becomes worse after some intercurrent illness- $\omega_{\mathrm{G}}$ but it seems to be more or less natural for a skin disease to improve during such an illness. A history of onset after an accident to some third $\vec{A}$ party after taking medicine for some unrelated condition is suspicious. Fantastic stories (e.g. how $\vec{c}$ a fly got in the eye, travelled down the naso- $\frac{c}{5}$ lacrymal duct and flew out of the nose, ever since $\mathbb{D}$ when the cheek has been swollen) need no com $\overrightarrow{0}$ ment, nor perhaps a history of intolerance $f$ reasonable and bland forms of local treatment.

Sometimes, of course, the patient tells us that sto has always had a 'delicate skin' or that such an infirmity runs in the family. She may even attribute the whole illness to ' nerves' or tell us $\frac{\not}{\Phi}$ quite frankly that ' scenes go to my hands.' She $\varrho$ may fail to remember important dates or happen- $\overrightarrow{\overrightarrow{0}}$ ings in the history of the disease or she may remember dates and symptoms only too well and keep a collection of hospital tickets, prescriptions, etc. She may admit to overt matrimonial diffi- 흘 culties. A man may complain of tiredness, a feeling of shakiness or heat and cold. There may be a history of other neurotic diseases, e.g. functional duodenal ulcer, or a frank story of $\frac{\bigcirc}{3}$ nervous breakdown. It often happens that a man will produce a voluminous written account of his illness; worse still it may have been written out $\frac{D}{0}$ for him by his wife. Family history may disclose that the patient's father was invalided out of the o Army with the same condition. The family history is always important. The significance of uni- or $N$ primo-geniture is well known, but hardly less $\omega$ important is the position of the second girl or the boy born after a series of five or six girls. It often $\frac{0}{C}$ seems to happen too that there has been an invalid, next in order of geniture on either side of the ? patient, who may have absorbed an undue share $\frac{0}{\circ}$ of care and attention. 
Nobody needs to be warned against the 'urgent' case or the patient who proclaims the superiority of the herbalist over the scholarly consultant, or the patient who is constantly changing his doctor or has already seen several consultants. Patients who are voluble about allergy and vitamins, the politely unbelieving or frigid patient, the dependent personality, the aggressively suspicious one, the patient with a Mona Lisa smile or the expression of a cat having eaten the canary, or having an unnatural indifference to pain may be mentioned here. The sudden urge for the removal of lifelong moles or blemishes or the neglect of serious and disfiguring lesions may have to be taken into account in assessing the patient. Unusual precautions to maintain health, for instance massaging the feet with oil every night in order to counteract the effect of having to stand at work or attribution of the disease to dirt, the smell of drains, the circumstance that $r$ ats or even foreigners had previously infested the house lived in or statements by the patient that his house is dilapidated or that he is trying to find a new one are not without significance.

When we come to study the history of the lesion and its onset we may get a fantastic and involved account of dirty towels or water contaminated at its source, or we may be astonished that an educated patient who knows perfectly well that diluted $\mathrm{H}_{2} \mathrm{SO}_{4}$ is fairly harmless to the skin should attribute the whole of a ten-year illness to a momentary and reactionless contact. A patient with a familiar condition, for example pruritus ani, may complain of the wrong symptoms, as for example a shiver up the spine or discomfort in walking. The words 'terrifying' and 'murder' may be used in the description of what can clearly only be minor symptoms. Sometimes the patient will attribute signs and symptoms arising in other: systems to unlikely causes, for example Dupuy-œ tren's contracture to having tried to milk az cow.

When we come to talk to the patient about $\stackrel{2}{\mathrm{C}}$ herself she may tell us of unusual or obsessive $\overrightarrow{\vec{F}}$ habits, that she never eats tinned food, never allows $\stackrel{\oplus}{?}$ herself to cry or that her habits are so clean that? she scrubs her vulva with a loofah dipped in $\overline{\bar{N}}$ Dettol twice a day, or that she demands to be $\frac{\bar{\sigma}}{\sigma}$ treated by hypnosis. A man may confess to stamp $\propto$ collecting or model railways or to his preference for a labourer's job to his own skilled trade. Or $\rightarrow$


not having worked for months or years he will $\vec{\omega}$ confidently assert the miraculous ' if it were not $\stackrel{\text { }}{\circ}$ for my skin I could do better work than any of 0 them.' Perhaps more significant than anything is 3 . the remark, 'I haven't a worry in the worldexcept my skin.'

As the end of the consultation approaches we Iु may notice that the patient is still tense and $\omega$ obviously unsatisfied. This should be a useful $\vec{P}$ hint to us that an opportunity is waiting to be을 seized. And sometimes the patient will wait until he is nearly outside the door before disclosing the $\subseteq$

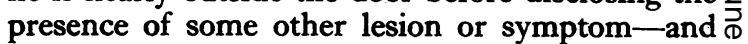
this is usually the very one about which he hąs $\overrightarrow{0}$ really come to see us.

Finally, supposing that we have missed all the indications above described and the patient come back again and shows us that he fails to respond at all to our best therapeutic efforts or he demonstrates an over-anxious watchfulness for the $\frac{\mathscr{Q}}{\mathcal{Q}}$ slightest sign of relapse or, finally, having at last $\supseteq$ gone back to work he comes back the next day as $\overrightarrow{\overrightarrow{0}}$ bad as ever again, surely we can no longer close 3 our eyes to the real nature of his malady!

\section{'AROXINE'}

Burroughs Wellcome \& Co. announce the introduction, in the United Kingdom, of 'Aroxine' brand pessaries, containing $75 \mathrm{mg}$. of 2formamido-5-nitrothiazole in each product. 'Aroxine' is indicated for the topical treatment of Trichomonas vaginalis vaginitis-trichomoniasis. In a comparative clinical trial the therapeutic efficacy of 'Aroxine' was found to be about equal to that of acetarsol. 'Aroxine' contains no arsenic and will not, therefore, give rise to the reactions which occasionally result from the topical use of arsenical $N$ compounds.

'Aroxine' pessaries incorporate a foaming base to promote rapid and extensive dispersion. They are available in bottles of 30 and tins of 500 . 'Aroxine' is not subject to control under the Poisons Rules. 